\title{
Low-Pressure Casting of Aluminium AlSi7Mg03 (A356) in Sand and Permanent Molds
}

\author{
Franco Chiesa $^{1 *}$, Bernard Duchesne ${ }^{2}$, and Gheorghe Marin ${ }^{1}$ \\ ${ }^{1}$ Centre de Métallurgie du Québec, 3095 Westinghouse, Trois-Rivières, Qc, Canada G9A 5E1 \\ ${ }^{2}$ Collège de Trois-Rivières, 3500 de Courval, Trois-Rivières, Qc, Canada, G9A $5 E 6$
}

\begin{abstract}
Aluminium A356 (AlSi7Mg03) is the most common foundry alloy poured in sand and permanent molds or lost-wax shells. Because of its magnesium content, this alloy responds to a precipitation hardening treatment. The strength and ductility combination of the alloy can be varied at will by changing the temper treatment that follows the solutionizing and quenching of the part. By feeding the mold from the bottom, the low-pressure process provides a tranquil filling of the cavity. A perfect control of the liquid metal stream is provided by programming the pressure rise applied on the melt surface. It compares favorably to the more common gravity casting where a turbulent filling is governed by the geometry of the gating system.
\end{abstract}

\section{The low-pressure permanent mold process}

The low-pressure permanent mold casting (LPPM) [1], schematized in Figure 1a and shown in Figure $1 \mathrm{~b}$ and $1 \mathrm{c}$, is a common process producing high quality castings resulting from two main characteristics:

1) The perfectly controlled quiescent filling from the bottom of the mold when compared to the turbulent flow associated with gravity casting; also, the liquid metal is drawn up the transfer tube from under the melt surface, preventing dross entrainment into the mold cavity.

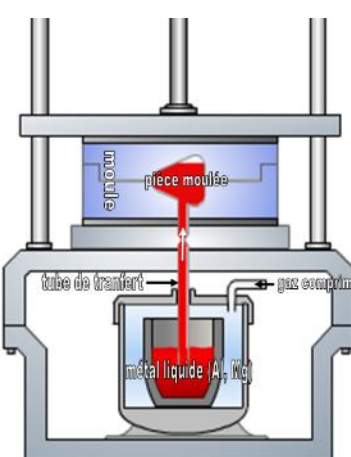

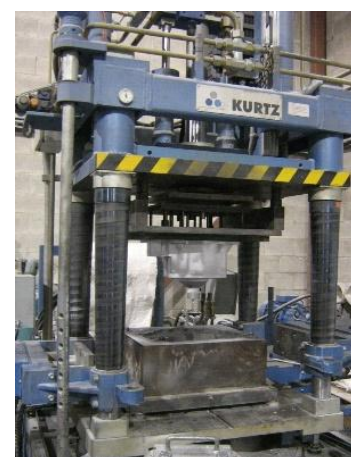

b

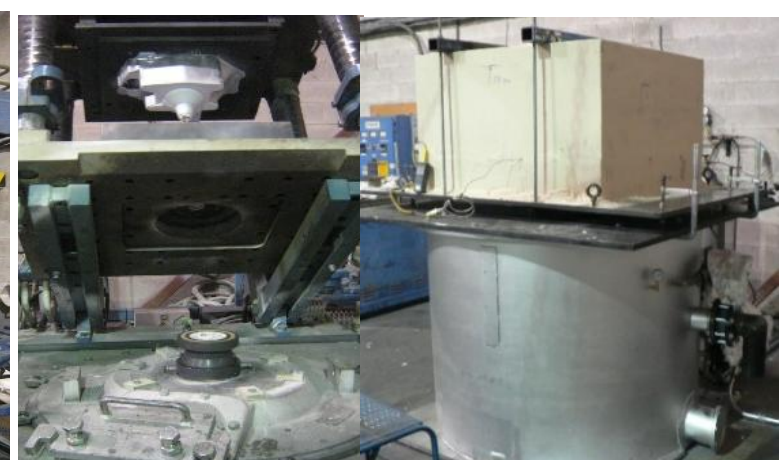

d

Fig.1. Principle of the low-pressure casting (a), with a permanent mold (b, c) and a sand mold (d).

\section{Conversion of a gravity poured sand cast bellhousing to a low- pressure permanent mold one}

When the order for a bellhousing designed for racecars reached one thousand units a year, it became economical to consider switching from sand casting to permanent mold. Indeed the productivity of permanent mold is higher than that of sand molding in terms of parts produced

\footnotetext{
*Corresponding author: franco.chiesa@cegeptr.qc.ca
}

2) The very efficient feeding achieved via the bottom feeder tube by applying a pressure of up to one atmosphere to the melt; the resulting yield is very high, typically $80-90 \%$ versus $50-60 \%$ for gravity casting. However, the low-pressure process cannot pour any casting geometries. Low-pressure sand casting (LPS) is much less common than LPPM; the sand mold rests on top of the pressurized enclosure as shown in Figure 1d. The similarity between LPPM and LPS lies in the controlled quiescent filling of the mold with a dross-free melt; both processes also share the ability to pour thinner castings than gravity pouring would. per day-employee. However, the tools and capital costs are typically 10 times more in permanent mold and the economic break-even point can be easily worked out when the cost of the tooling is known. As we will see, permanent mold provides substantially higher mechanical properties, which is particularly important in the realm of amateur car racing, as most of these parts will be used until failure. Like in passenger car wheels, the shape of the bellhousing lends itself particularly well to low-pressure casting. Low-pressure is more expensive in capital cost than gravity casting but offers a cleaner metal, as mooth controlled filling and a higher yield and productivity. 


\subsection{The original gravity poured sand bellhousing}

The belhousing is $400 \times 350 \times 165 \mathrm{~mm}$ in overall size and weighs $7.0 \mathrm{~kg}$. In gravity sand casting, making up for the loss in volume accompanying solidification (i.e. "feeding" the casting) is insured by four $40 \mathrm{~mm}$ diameter insulated risers and one conical flow-off, $30 \mathrm{~mm}$ in diameter at its base (Figure 2). The AlSi7Mg (A356) melt was poured at $740^{\circ} \mathrm{C}$ after refining with Al5Ti1B (15 ppm B) and degassing with argon to a reduced pressure test sample density of 2.60 or 0.12 $\mathrm{ml} / 100 \mathrm{~g}$ of hydrogen [2] (Mulazimoglu, 1989). The gating system (sprue/runners/gates aeras ratio is $1: 4: 4$ ) imposes a filling time of 14 seconds. Two castings were poured from a melt, the composition of which is given in Table 1 .
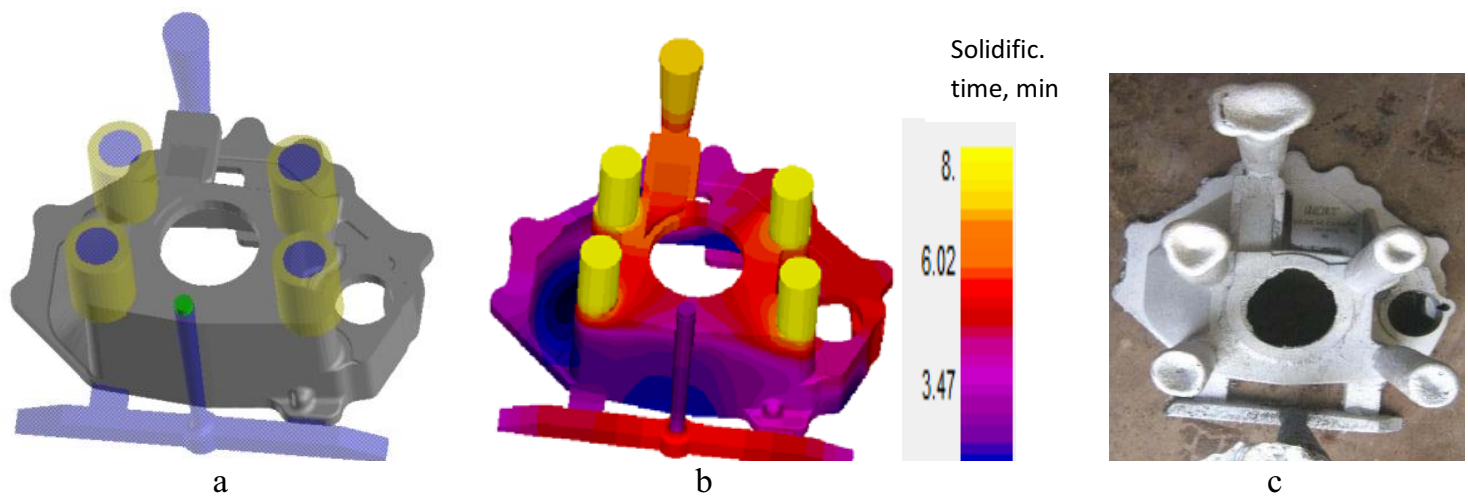

Fig. 2. a) Model of the sand cast bellhousing - b) Solidification sequence (min) - c) Casting at shakeout.

Table 1. Composition of the gravity sand poured AlSi7Mg03 (A356) casting.

$\begin{array}{lccccccccc}\text { Element } & \mathrm{Si} & \mathrm{Fe} & \mathrm{Cu} & \mathrm{Mn} & \mathrm{Mg} & \mathrm{Zn} & \mathrm{Cr} & \mathrm{Ti} & \mathrm{Sr} \\ \text { Mass \% } & 6.56 & 0.05 & 0.01 & 0.00 & 0.31 & 0.06 & 0.00 & 0.12 & 0.001\end{array}$

As shown in Figure 2b, the solification time in the casting varies between 1.2 and 8.0 minutes. The castings were heat treated to a "soft" T6; i.e solutionized for $8 \mathrm{~h}$ at $540^{\circ} \mathrm{C}$, then quenched in $65^{\circ} \mathrm{C}$ water and aged for 4 hours at $155^{\circ} \mathrm{C}$.

\subsection{The low-pressure poured bellhousing}
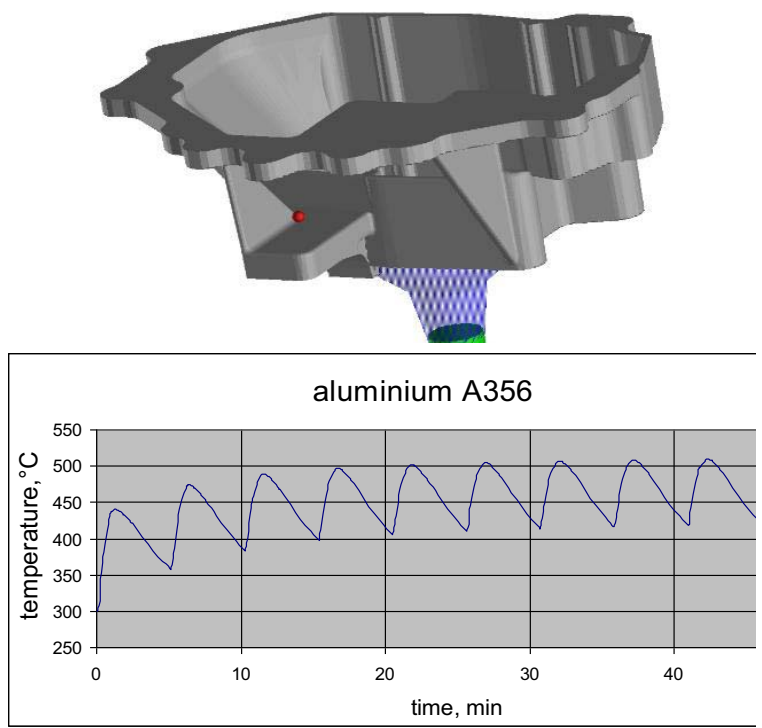

Fig. 3. Model of the low-pressure casting and predicted temperature cycling at the red dot.
Contrary to what takes place in gravity casting, the low-pressure process gives a total freedom in selecting the filling time; it was chosen at 4 seconds by applying a pressure ramp of $10 \mathrm{mB} / \mathrm{s}$ on the melt. As seen on the model of Figure 3, the ratio of the casting weight/alloy poured is higher than in gravity casting $(0.87$ versus 0.68$)$, which is typical of low-pressure permanent mold casting. As seen on the graph of Figure 3, the dynnamic thermal equilibrium is reached after 8 castings are poured when the initial temperature of the mold is $300^{\circ} \mathrm{C}$. The production rate is close to 12 castings/hour.

The feeding of the casting is insured by applying a pressure of $900 \mathrm{mB}$ on the melt, corresponding to an aluminium pressure head of $3600 \mathrm{~mm}$, compared to $100 \mathrm{~mm}$ in the sand cast set-up. However, for adequate feeding of the casting, directional solidification must take place from top to bottom, in the direction of the transfer tube. The Grade 40 grey iron mold was originally machined at the dimensions of the gravity cast bellhousing. In the early trials, shrinkage appeared at several locations which were easily pinpointed as "hot spots" by solidification modeling (Fig. 4). 

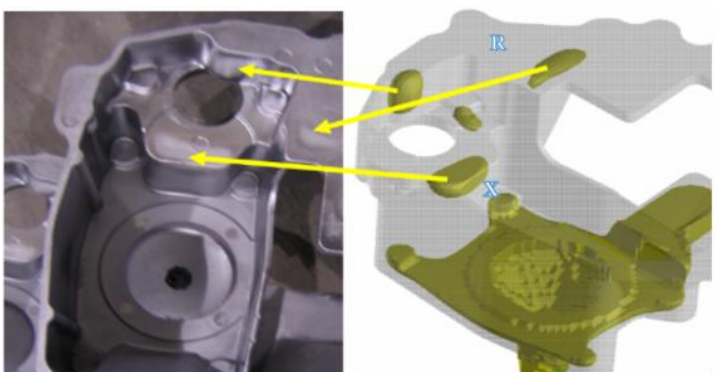

Fig. 4. Shrinkage in the first low-pressure castings and corresponding "hot spots" in the thermal model

In sand casting, chills and risers are used to achieve directional solidification, which is not the case in permanent mold casting. The solutions of the problems highlighted in Figure 4 were as follows:

1) Reducing the thickness of the base flange from 13 to $11 \mathrm{~mm}$, which was possible because of the higher strength of the permanent mold cast part versus the sand cast one.

2) Reducing the mass of alloy at location $R$ by molding a previously drilled $10 \mathrm{~mm}$ hole.

3) Padding the casting at location $X$ to ensure a feeding path towards the transfer tube.

The melt was argon degassed for $20 \mathrm{~min}$, refined with $15 \mathrm{ppm}$ of boron (A15Ti1B) and modified with $120 \mathrm{ppm}$ of strontium (A110Sr); contrary to the practise in sand casting, where many consider that modification increases the risk of hydrogen pick up, modification is the rule in permanent mold casting. The melt was then poured at $720^{\circ} \mathrm{C}$ because of the short filling time. The composition of the A356 alloy cast in lowpressure is given in Table 2. As shown in Figure 5 , the predicted solidification time in the LPPM bellhousing varies from 0.20 to $3.6 \mathrm{~min}$, expectedly much shorter than in the sand cast part (1.2 to $8.0 \mathrm{~min}$ )

Table 2. Composition of the alloy A356 poured by low-pressure

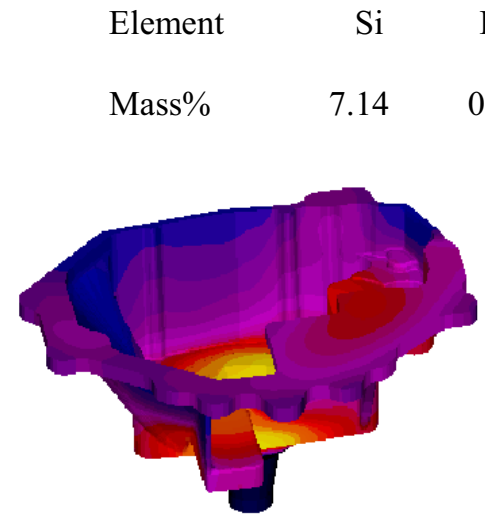

Fig. 5. Predicted solidification time

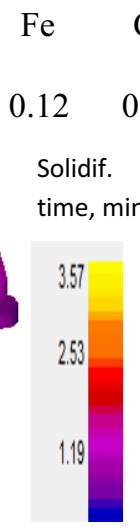

$\mathrm{Cu}$

0.03

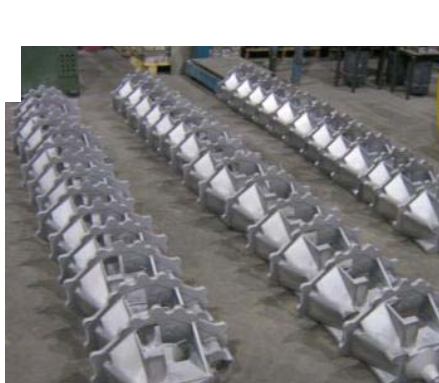

Produce of a 4 hour casting run
$\mathrm{Cr} \quad \mathrm{Ti} \quad \mathrm{Sr}$

$0.01 \quad 0.10 \quad 0.012$

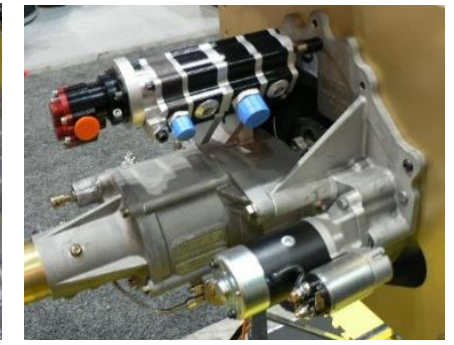

Mounted bellhousing
The LPPM castings were heat treated to a harder T61 temper, i.e. solutionized for $8 \mathrm{~h}$ at $540^{\circ} \mathrm{C}$, then quenched in $65^{\circ} \mathrm{C}$ water and aged for 8 hours at $155^{\circ} \mathrm{C}$ instead of $4 \mathrm{~h}$ for the sand cast bellhousing. This was possible because the permament mold process provides a higher ductility than the sand process for identical heat treating conditions, so that bringing the temper closer to peak aging did not bring about a lower ductility (versus the sand cast part) while allowing to achieve higher yield and ultimate tensile strengths (YS and UTS).

\section{Mechanical properties of the gravity sand cast and the low- pressure bellhousings}

Mechanical properties may vary considerably within the same casting due to different solidifying conditions [3] (Chiesa, 2018). The properties depend mainly on the local solidification time (time elapsed between the beginning and end of solidification) and to a lesser degree, on the thermal gradient in the direction of the feeders. Note that the thermal gradient is mathematically tied to the solidus velocity; a high thermal gradient corresponds to a low solidus front velocity and either may be used in predicting the metallurgical and mechanical properties at a location id the casting as will be later shown (Equation 1).

Round and flat tensile tests bars were excised at 3 locations from a pair of castings 
produced via each process; this was done at locations T, $\mathrm{S}$ and $\mathrm{W}$ indicated in Figure 6. The specimens reduced sections were $6 \mathrm{~mm}$ in diameter for round specimens and $6 \times 12 \mathrm{~mm}$ for the flat ones. Since two castings per process were used, the average of the yield strength (YS), ultimate tensile strength (UTS) and elongation (El) were calculated from the results of four samples at locations $\mathrm{T}$ and $\mathrm{F}$ and of eight samples at location $\mathrm{W}$ excised from 2 castings.

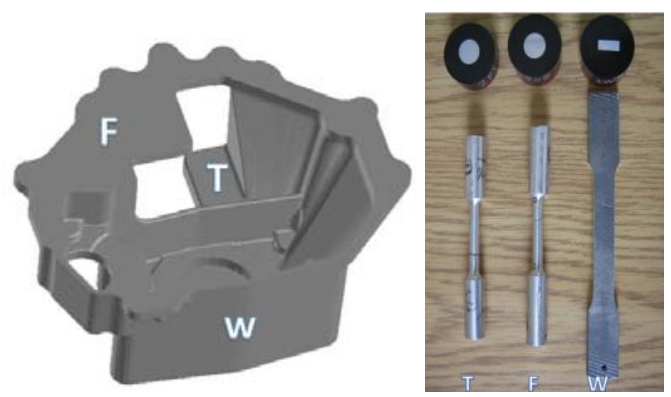

Fig. 6. Location of the tensile test bars T, F, W excised from the sand and low-pressure permanent mold castings

The results of the tensile tests are shown in the graph of Figure 7; the average and the standard deviation are indicated for the three locations and the two processes. The spread in the results is higher in LPPM, which is particularly noticeable on the elongation results. This will be explained later in the present section.

The secondary dendrite arm spacing, DAS, depends only on the local solidification time; it is thus smaller in permanent mold, and smallest in the $\mathrm{W}$ test bars. The porosity is also less for short solidification times, but also less with a good local feeding, which requires a strong positive thermal gradient in the direction of the feeder (or a low solidus velocity).

The finer metallurgical structure and the lower porosity of the permanent mold bellhousings explain their superior tensile properties when compared to those of the sand castings. However, the repeatability of the sand cast properties is better than the low-pressure one because the initial temperature or the mold (i.e. room temperature) is much more repeatable than in permanent mold as the thermal régime may be disrupted by changes in mold opening time due to ejection incidents, mold coating retouch, etc., so that the thermal dynamic equilibrium fluctuations are inevitable. The predicted thermal history in Figure 3 represents a perfect situation where filling of the cavity, mold opening and mold closing times would be repeated identical at each cycle, which is an unrealistic expectation in a production context. The $8 \mathrm{~h}$ aging time of the LPPM castings results in a higher yield strength than that of the sand castings (which was aged for $4 \mathrm{~h}$ ) while still retaining a higher ductility as represented by the elongation at break of the tensile test.

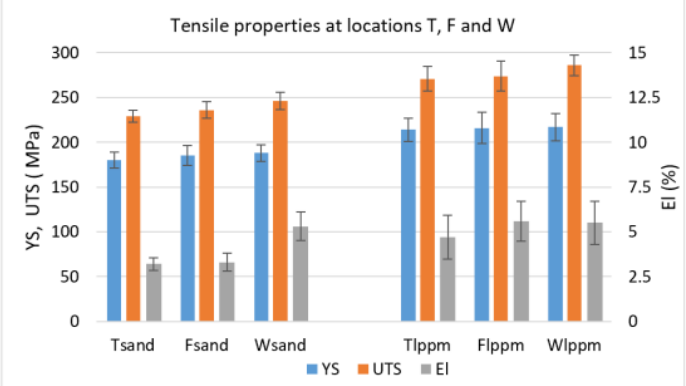

Fig. 7. Tensile properties at three locations in the sand and the LPPM bellhousings

\section{Metallographic observations}

Sections of the tensile samples were observed under an optical microscope; the level of microposity was determined by image analysis on the mosaics shown in Figure 8. The level of porosity is indicated along with the secondary dendrite arm spacing (DAS).
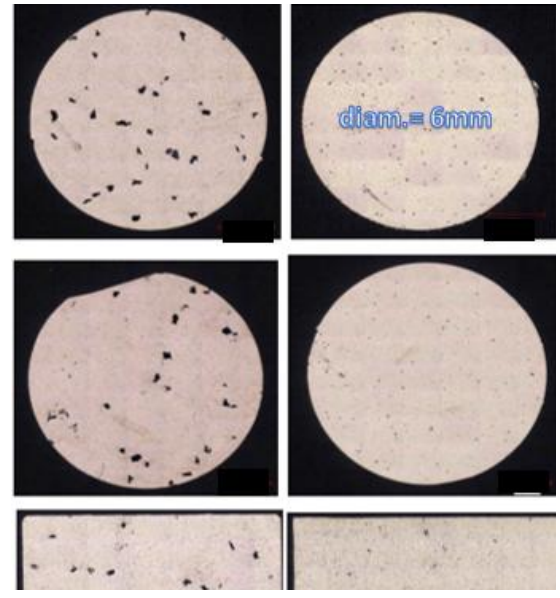


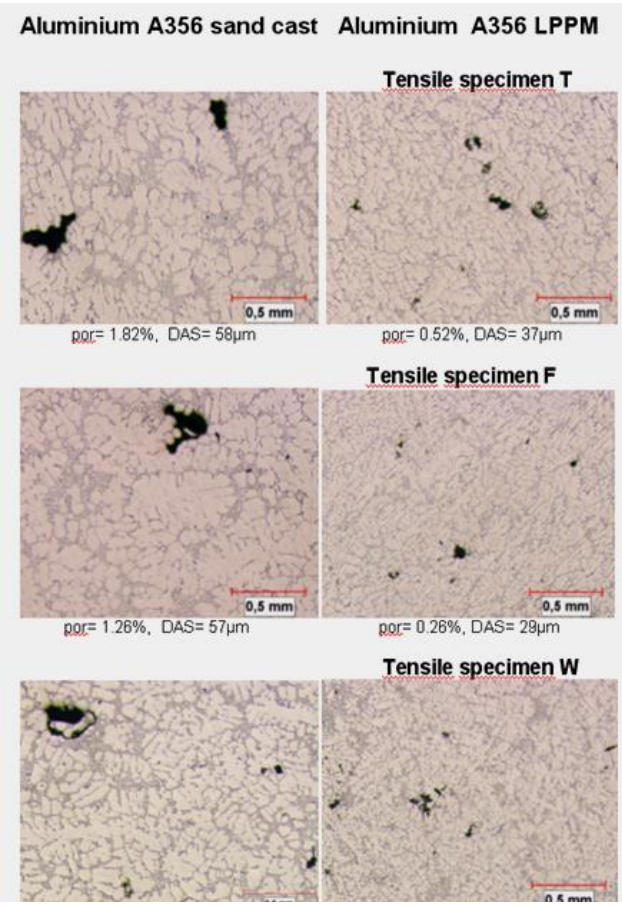

Fig. 8. Mosaics of tensile test bars T, S, W (left, from top to bottom) and corresponding micrographs 


\section{Predicting local tensile properties via solidification modeling}

The quality index $\mathrm{Q}$ is a convenient tool to assess the metallurgical quality of Al-Si-Mg alloys (A356, 357). Q lumps strength and ductility together and gives a value in $\mathrm{MPa}$ independent of the alloy temper [4](Drouzy, 1980):

$$
\mathrm{Q}=\mathrm{UTS}+150 \log \mathrm{El}
$$

In a previous study [5](Chiesa, 2006) showed that the quality index $\mathrm{Q}$ could be predicted inside a casting if a solidification modeling was performed. $\mathrm{Q}$ depends on the local solidification time $\mathrm{t}_{\mathrm{sl}}$ in $\mathrm{min}$ and the solidus velocity $V_{s}$ in $\mathrm{cm} / \mathrm{min}$ via the relationship:

$$
\mathrm{Q}(\mathrm{MPa})=465-10 \mathrm{t}_{\mathrm{sl}}^{2 / 3} \mathrm{~V}_{\mathrm{s}}^{1 / 5}-60 \mathrm{t}_{\mathrm{sl}}^{1 / 3}
$$

for an alloy A356-T6 degassed to $0.1 \mathrm{ppm}[\mathrm{H}]$

When this equation is applied to the results of the solidification modeling, the maps of Figure 8 are obtained for the sand and LPPM castings respectively.
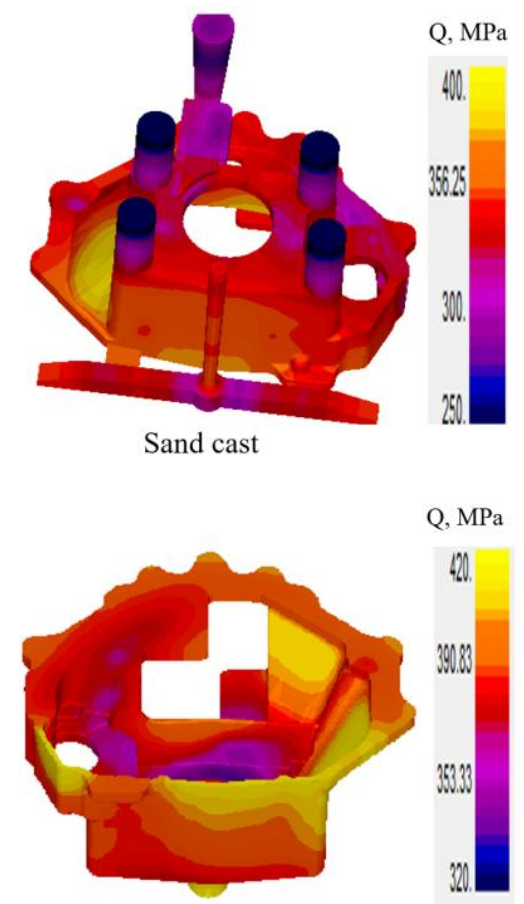

Low nressure nermanent mold cas

Fig. 9. Predicted distribution of the Quality index $Q$ in the sand and LPPM castings

\subsection{Calculation of UTS and El from the values of $Q$ and $Y S$}

In A356/357 alloys, YS, UTS and El are related by the relationship [6](Jacob, 1999):

YS $(\mathrm{MPa})=\mathrm{UTS}-60 \mathrm{Log} \mathrm{El} \%-13$

Since UTS $=$ Q - 150 Log El, the above equation may be re-written as:

$$
\begin{array}{ll} 
& Y S=Q-210 \log E l-13 \\
\text { or } \quad & \log E l=(Q-Y S-13) / 210
\end{array}
$$

Hence, the values of El \% and UTS may be calculated from the knowledge of Q and YS:

$$
\begin{aligned}
& \mathrm{El}=10^{(\mathrm{Q}-\mathrm{YS}-13) / 210} \\
& \mathrm{UTS}=\mathrm{Q}-150(\mathrm{Q}-\mathrm{YS}-13) / 210
\end{aligned}
$$

The yield strength YS has been shown to depend only on the magnesium content of the alloy and the temper treatment; for the present conditions, using the graph from [6] page 222, the results are as follows:

$$
\begin{aligned}
\text { Sand cast: } \% \mathrm{Mg} & =0.31 \% \text { aged } 4 \mathrm{~h} \text { at } 155^{\circ} \mathrm{C} \\
\mathrm{YS} & =187 \mathrm{MPa} \\
& \\
\text { LPPM cast: } \quad \% \mathrm{Mg} & =0.34 \% \text { aged } 8 \mathrm{~h} \text { at } 155^{\circ} \mathrm{C} \\
\mathrm{YS} & =222 \mathrm{MPa}
\end{aligned}
$$

\begin{tabular}{|c|c|c|}
\hline \multicolumn{3}{|c|}{$\mathrm{Mg}=0.31 \%$, aged for $4 \mathrm{~h}$ at $155^{\circ} \mathrm{C}$} \\
\hline \multicolumn{2}{|c|}{$\mathrm{YS}=187 \mathrm{MPa}$} & \\
\hline $\mathrm{Q}, \mathrm{MPa}$ & UTS, MPa & \\
\hline 300 & 229 & \\
\hline 320 & 234 & \\
\hline 340 & 240 & \\
\hline 360 & 246 & \\
\hline 380 & 251 & \\
\hline
\end{tabular}

\begin{tabular}{|c|c|c|}
\hline \multicolumn{2}{|c|}{$\mathrm{YS}=222 \mathrm{MPa}$} & \\
\hline $\mathrm{Q}, \mathrm{MPa}$ & UTS, MPa & El, \% \\
\hline 340 & 265 & 3.2 \\
\hline 360 & 271 & 3.9 \\
\hline 380 & 276 & 4.9 \\
\hline 400 & 282 & 6.1 \\
\hline
\end{tabular}

Applying equation 1 and 2 with YS $=187 \mathrm{MPa}$ and $\mathrm{YS}=222 \mathrm{MPa}$ gives the results in Table 3 .

Table 3. UTS and Elongation as a function of the Quality index Q, for the conditions of the sand (top) and LPPM castings (bottom).

$\mathrm{Mg}=0.34 \%$, aged for $8 \mathrm{~h}$ at $155^{\circ} \mathrm{C}$

When the Q scales in the maps of Figure 9 are narrowed, the values of the Quality index can be accurately determined at location $\mathrm{T}, \mathrm{F}$ and $\mathrm{W}$ for the sand and LPPM castings:

Sand casting: 306,301 and $365 \mathrm{MPa}$ at locations $\mathrm{F}, \mathrm{T}$ and $\mathrm{W}$

LPPM casting: 367,388 and $396 \mathrm{MPa}$ at the same locations

Refering to the results in Table 3, the predicted values of UTS and El can be determined. These predicted values are compared to the experimental ones in Figure 10. 


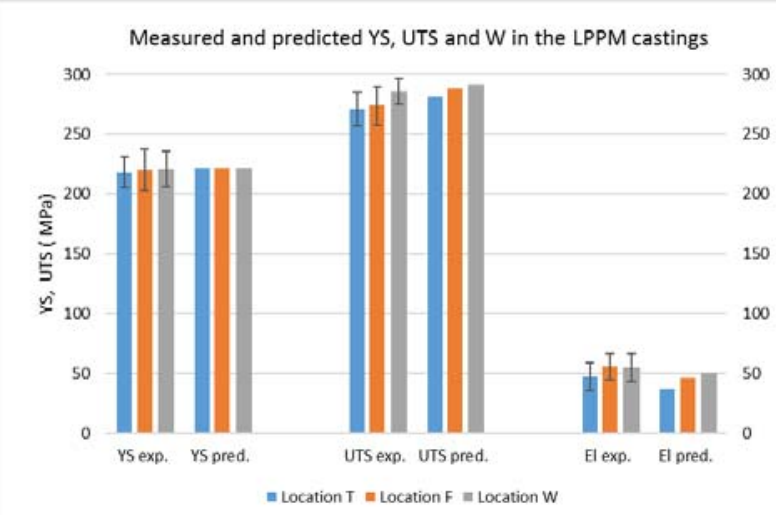

Measured and predicted YS, UTS and El in the sand castings

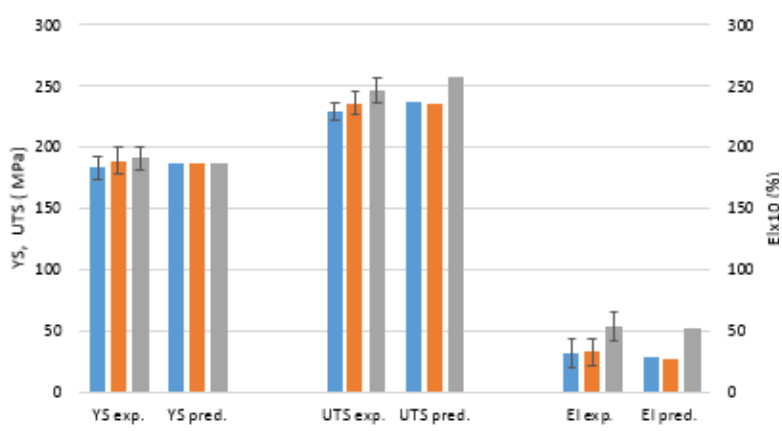

Fig. 10. Comparing experimental and predicted values of YS, UTS and El at 3 locations in the casting.

The agreement between predictions and experiments is reasonable and proves that the tensile properties can be reliably predicted for a casting poured from a clean and degassed AlSiMg melt, as long as the magnesium content and temper conditions are known. Alternatively, it is possible to determine the temper conditions necessary to achieve a set value for the elongation at a designated zone of a casting.

\section{Low-pressure filling of a sand cast tank}

The mold, $1200 \times 1800 \times 1800 \mathrm{~mm}$ in size is shown in its filling position on the low-pressure machine at the top of Figure 11. The tank after shakeout is on the right of the same figure, upside down with respect to its position when poured by lowpressure. The runners are fed by an uncoated 1.6 $\mathrm{mm}$ thick steel tube; no noticeable iron pick-up was detected, which is not surprising given that the residence time of the melt in the tube is about one second. A thermocouple was inserted in the runner in order to make sure that it was fully solidified (around $12 \mathrm{~min}$ ) when the mold was removed from the machine. The filling time was set to 20 seconds, resulting in a liquid metal velocity in the gates of $0.32 \mathrm{~m} / \mathrm{s}$, well below the critical velocity above which aluminium oxidation occurs [campbell]. The temperature of the liquid metal front is shown in Figure 12 (a) as it fills the mold cavity; it shows that the coldest metal front temperature is $690^{\circ} \mathrm{C}$, i.e. $70^{\circ} \mathrm{C}$ above the solidus temperature of the alloy.
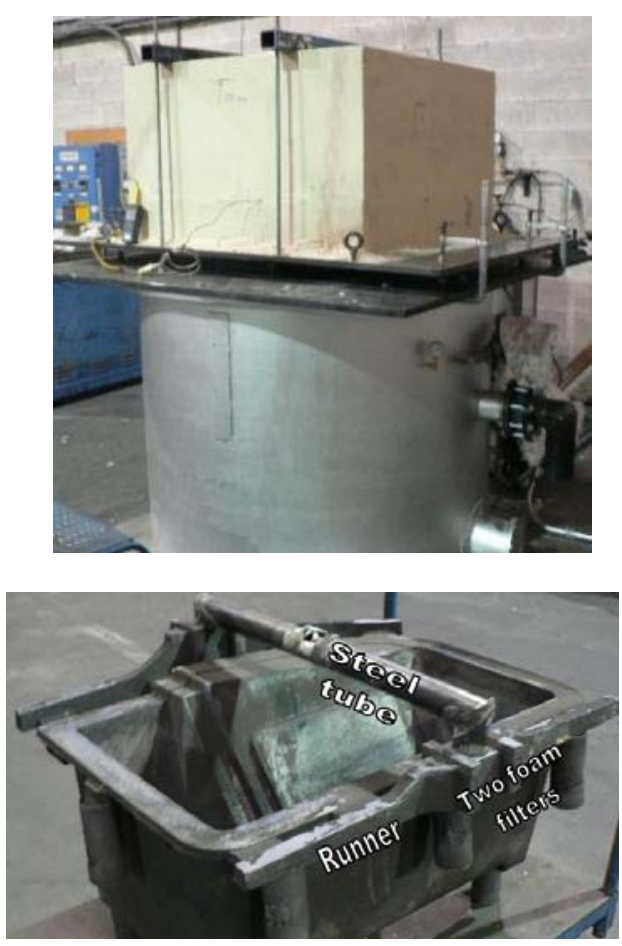

Fig. 11. The mold on the low-pressure machine (top); The casting at shakeout with its gating system (bottom)
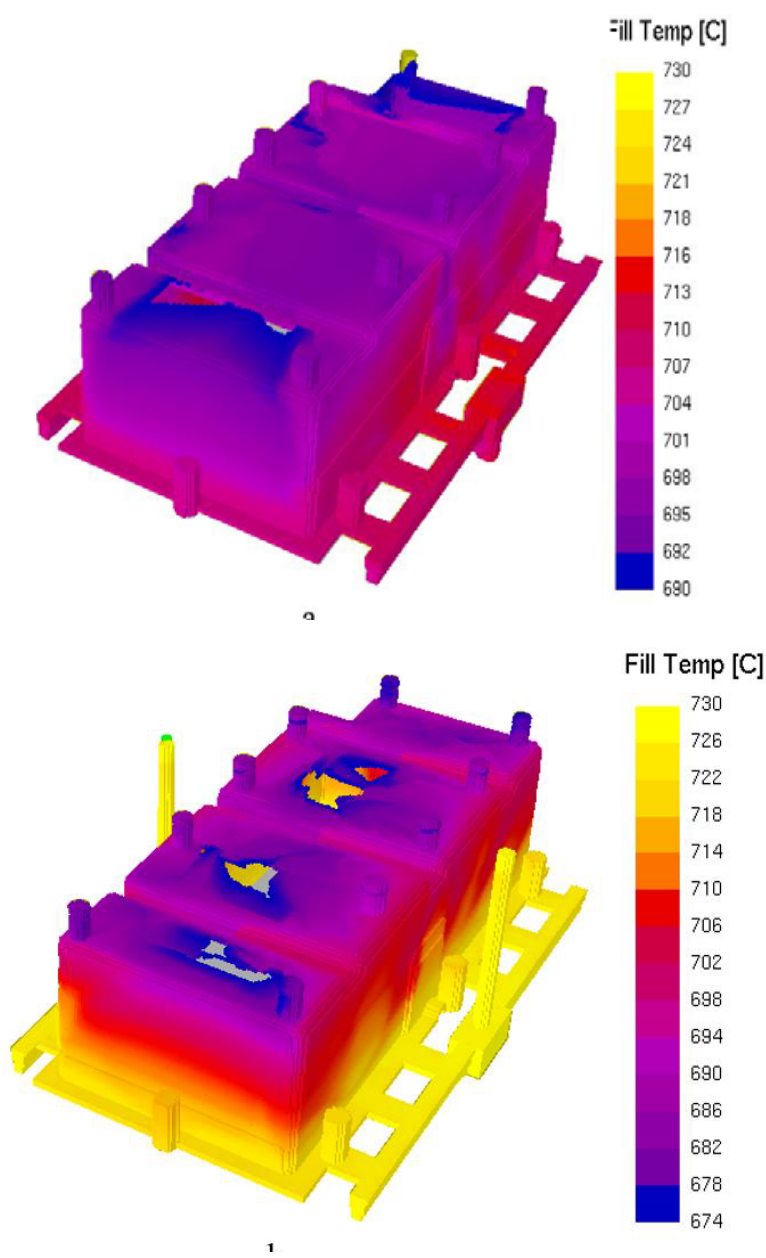

Fig. 12. Temperature of the liquid metal front during the filling: a) by low-pressure; b) by gravity 
If one considers filling the mold by gravity for the same maximum gate velocity of $0.32 \mathrm{~m} / \mathrm{s}$, since the filling slows down as the liquid metal rises in the cavity (it takes $7.5 \mathrm{~s}$, or $25 \%$ of the fill time to fill the last $10 \%$ of the mold cavity), the filling time must be increased to $30 \mathrm{~s}$; this is obtained with a tapered sprue bottom diameter of $40 \mathrm{~mm}$; the consequent liquid metal front temperature is that of Figure $12 \mathrm{~b}$. In gravity casting, the coldest liquid metal front is $674^{\circ} \mathrm{C}$, i.e. $16^{\circ} \mathrm{C}$ lower than in lowpressure. This demonstrates the higher capacity of the low-pressure process to produce thin castings in sand molds; the same has been demonstrated to be the case in permanent mold castings [8].

\section{Conclusions}

Because of their shorter solidification time, the bellhousings cast by low-pressure permanent mold (LPPM) exhibit better tensile strength and ductility than those cast in sand molds. However, in lowpressure casting, the shape of the casting must be such that directional solidification is insured from the top to the bottom of the casting where the feeding tube is located. In sand casting, nondirectional solidification may be tackled with risers, which is not the case in permanent mold. Compared to gravity casting, LPPM involves a cleaner melt because the liquid alloy is drawn from under the melt surface. Low-pressure casting results in a much better yield than gravity casting (i.e. casting weight/poured metal weight of $80-90 \%$ versus $50-60 \%$ typically for gravity casting).

The concept of the quality index allows predicting the yield strength, ultimate tensile strength and elongation in AlSiMg alloys when the magnesium content, the aging time and temperature are known.

The low-pressure sand casting is a very productive process which should first come to mind when large premium quality aluminium castings must be produced. The process should also be considered when walls are too thin to be obtained by gravity casting (e.g. $3 \mathrm{~mm}$ over a $400 \mathrm{~mm}$ height). However the shape of the casting must lend itself to the process, so that directional solidification is maintained throughout the solidification process.

The authors wish to acknowledge the support of the NSER Council of Canada and the Quebec MESI Ministry. This study was conducted within the framework of the REGAL aluminium research centre.

\section{References}

1. D. Neff, S.P. Thomas, S.P., Aluminum Casting Technology, Third Edition, American Foundry Society Publications, ISBN-978087433-456-2, 293 (2018)

2. H. M. Mulazimoglu, N. Handiak and J.E. Gruzleski, J.E. (1989). Some Observations on the Reduced Pressure Test and Hydrogen Concentration of Modified A356 Alloy, AFS Transactions, 97, 225 (1989).

3. F. Chiesa et al., "How Properties Vary Throughout a Casting", Modern Casting, August 2018, 39 (2018)

4. M. Drouzy, S. Jacob and M. Richard, M, Interpretation of Tensile Results by Means of the Quality Index, AFS International Cast Metal Journal, June 1980, 43 (1980)

5. F. Chiesa, B. Duchesne and G. Morin, Proceedings of the International Symposium on Aluminium: From Raw Materials to Applications, CIMM Publications, 115 (2006)

6. S. Jacob, Quality Index in Prediction of Properties of Aluminium Castings - A Review, AFS Transactions, 107, 811 (1999)

7. J. Campbell, Complete Casting Handbook, Elsevier Publications. ISBN-13:978-1-85617809-9, 46 (2011)

8. F. Chiesa, J. Baril and P. Dubé P. (2009), Lights, Camera, Castings! Engineered Casting Solutions, March - April, 24 (2009) 